\title{
The main trends in the process of building the creative potential of engineering students
}

\author{
Rozaliya Akhmetgareeva*1, Nurgizya Khasanova ${ }^{1}$, and Meri Gulkanyan 1[0000-0001-6259-0171] \\ ${ }^{1}$ Kazan State University of Architecture and Engineering, 420043 Kazan, Russia
}

\begin{abstract}
The article discusses the main trends in the process of building creativity in engineering students. It is highlighted that the productivity of an engineer's activity is determined not only by modern techniques and technologies, but also by the personal potential of the engineer as a creator. The authors investigate the problem of shaping the qualities of a creative personality in engineering students and the development of professionally important competences. The authors' study of the views of various researchers made it possible to identify the main trends in the formation of creative thinking among students in a technical university. Particular attention is paid to the technical bilingualism of the future specialist. It becomes a prerequisite for future success in the profession. Fluent knowledge of a foreign language and the ability to read technical documentation in another language on a par with Russian makes an engineer in demand, and creates more realistic conditions for Russia's integration into the world system of industrial relations. Some directions for the development of students' creative thinking are shown.

Keywords. The productivity of the engineer, the main trends in the development of the creative personality, creative thinking, international technology area.
\end{abstract}

\section{Introduction}

Almost every day we all receive information about the coronavirus infection situation from various sources. University teaching staff, being on the «cutting edge» in terms of the number of social contacts since the introduction of restrictive measures, have been forced to switch to an online format, to learn and be able to work in various distance learning (DL) systems. Of course, direct verbalized, emotionally engaging contact between a teacher and a student cannot be replaced by distance communication, especially when it comes to the process of forming a creative personality. And the educational buildings, production laboratories, workshops, etc., the «spirit of engineering» embedded in them cannot be compared with the online format.

When considering the creative potential of a future university graduate, it should be noted that, for a very long time, the entire process of engineering specialist development was simply a technical policy. The production and technological aspect were the leading one, leading to a logic that was obsolete in every sense of the word to develop a new generation of specialists with creative outlines. The formation of man himself as the main productive force was

*Corresponding author: rozateacher@mail.ru 
regarded as simply a consequence of changes occurring in production under the influence of the development of science and technology. The opportunities for the development of a young specialist as a person were determined by the logic of technological development.

The circumstances which have arisen and exist today consider the achievement of an individual's position in the labour process which subordinates the logic of the development of various technical systems to the goal of the development and formation of the individual himself. The personal aspect of the characterisation of productive forces shows the individual in labour activity not only how he or she creates any benefits, but also how he or she realises his or her abilities. As a result we see that the formation and training of decent, competitive engineering staff is more important than ever before for the economic development of the state. There is an urgent need precisely for broad-based training of engineering staff. A future engineer should be able to adapt well to any production environment.

The search in this direction leads to the need to investigate current trends in the process of building creativity in engineering students. Creative activity is a property of an integral personality for whom socially significant work has a special value. By considering the main directions of development of creative projects in civil engineering students, we found that technical bilingualism becomes a prerequisite for future success in the profession. Fluent knowledge of a foreign language and the ability to read technical documentation in another language on a par with Russian makes an engineer in demand, and creates more realistic conditions for Russia's integration into the world system of industrial relations. There must be a clear understanding that a future engineer is a specialist who is fluent in his/her personal resources, able to solve any tasks of a complex nature well. We need an engineer who is able to work in the international technological space. Our research shows that universities need to attract specialists in all fields who have a good command of a foreign language. Today, English is particularly in demand as a language of international communication.

The creative potential of a specialist is inextricably linked to his or her creativity. In our study of various scientific works, we define creative activity as a characteristic of the whole person, for whom work itself has an independent value. The following authors paid attention to this problem: S.A. Atwood, J.E. Pretz [1], I. Badran [2], D. Cropley and A. Cropley [3], D.H. Cropley [4], S.R. Daly, E.A. Mosyjowski, S.L. Oprea, A. HuangSaad, C.M. Seifert [5], S. Drabkin [6], M. Karwowski [7], G. Scott, L.E. Leritz, M.D. Mumford [8], B. Shneiderman [9], R.V.V. Vidal [10], D.R. Waller [11], L.A. Zampetakis, L. Tsironis, V. Moustakis [12].

The formation of specialists' creative potential as a general pedagogical problem is explored in the works of C. Zhou [13], A. Craft [14], D. Davies, D. Jindal-Snape, C. Collier, R. Digby, P. Hay, A. Howe [15], S.R. Daly, E.A. Mosyjowski, C.M. Seifert [16], R.M. Felder [16], and in the works of others [17-34].

The concept of «creative activity», specific features of creative thinking formation within the walls of an engineering university are considered in the scientific works of a number of other contemporary authors [35-42].

\section{Materials and methods}

To solve these tasks, we used a set of research methods: analysis of the literature on the problem of research; analysis of training and curriculum documentation; educational experiment; testing and questioning. Mathematical statistics methods were used to process the results of the experiment.

The following ideas were used in the work: systemic and activity-based approaches, anticipation and design of educational systems. The theory of language competence of future engineers was chosen as the basic one. Empirical and theoretical methods have been used to solve the tasks. The empirical methods are based on experience, connected with observation, questionnaires, with the study of graduate engineers' performance. These methods were 
complemented by experiment, experimental work. The theoretical methods (analogy, modelling, system analysis) enabled to reveal the main contradiction of the research and to substantiate the psychological and pedagogical conditions for the formation of creative potential within the walls of an engineering university. The study was based at Kazan State University of Architecture and Engineering.

In the course of the experimental work, the main objects of control over the formation of creative thinking style among engineering students are the ability to solve complex tasks of a creative nature. The essence of the experiment was to identify the level of formation of the creative style of thinking in students. The experiment traced the dependence of the formation of creative potential on the implementation of a set of psychological and pedagogical conditions in the experimental groups. The comprehensive analysis allows us to suggest that the process of engineering personnel training with creative thinking style in the system of engineering university can be more effective if the following psycho-pedagogical conditions are implemented:

- the educational process is aimed at developing a set of professionally relevant competencies and readiness to transfer them to different areas of professional activity;

- the creative potential of the students is effectively shaped by complex and problembased tasks. A variety of non-standard situations and tasks recreate an atmosphere that is close to the realities of professional life in the classroom;

- the teachers need targeted psycho-pedagogical training in the area of the problem under study. The analysis of questionnaire data and interviews has shown that teachers, regardless of their pedagogical experience, have difficulties in developing and implementing professional tasks of a complex nature, and in posing problems in the classroom that require a synthesis of interdisciplinary knowledge. This is due to their lack of understanding of the essence of integration of diverse knowledge (technical, special, psycho-pedagogical, etc.) and the integrative nature of engineering activity. Teachers are not sufficiently aware of the changes that are taking place in science, technology and the psychology of the modern student.

\section{Results}

In the course of a comprehensive analysis and study of the results of the educational process, we found that for students actively involved in scientific and technical creativity, motives related to the orientation to the content of future work, the demand for this profession, material satisfaction with the results of their work are predominant. Creativity, as an integral part of work activity, develops along its own trajectory. If we consider creative potential as a component of personal potential, we see the following outline. Creative potential is first and foremost a specialist's ability to engage in productive activities that are unique and original. In the process of his formation as a person and creator, we see his unique, inimitable ideas, masterpieces of creative labour. The dynamics of a specialist's creative potential is determined by the ratio of the main components of this potential - the specialist's ability and capacity for creative activity. The listed constituent parts of the potential must be seen as its objective and subjective conditions, constituent parts that fix internal, substantive contradictions of the potential as a whole. Research conducted over the years suggests that when objective and subjective conditions are in a certain correspondence, when the highest level of their development is reached, favourable conditions can be created to trigger the mechanism of creative activity of a specialist. A disturbance of this balance significantly slows down the growth of creativity and may lead to a decline in interest in work and a clear expression of a negative attitude towards work. Some specialists in recent years even believe that it is our Russian specialist as a creator who has a special national code, capable of overcoming engineering barriers.

Today, current educational programmes aim at a comprehensive system of intellectual and psychological development, which forms the various components of a creative style of 
thinking in the learner. The main feature of this style of thinking as an intellectual system is the ability to analyse any problems, establish systemic connections, identify contradictions, find solutions for them, predict possible variants of development of such solutions, etc. The very readiness for activity with creative outlines is determined by the independent ability to search for creative problem-solving options at logical and intuitive levels; the presence of systemic inter-scientific knowledge of a high level of generalisation; and the ability to see the technical object itself. An individual with this style of thinking is not only ready for constant change in technology, but instead views it as an opportunity to gain vital moral satisfaction from the intellectual challenges that arise. The formation of a creative personality and the development of practice-oriented competences among university students is a crucial task, the solution of which is essential for economic development.

Despite the recent increase in research on creative thinking, the concept of creative thinking' itself is rarely explored. This is most often done through a more general definition - «creativity». Some researchers believe that creative thinking is a neutral psychological part of creative activity. The main component of the thought process in solving a problem is precisely the transfer of old accumulated experience to new given conditions. We agree with the researchers who define creativity as a certain property of the whole person for whom work has an independent value. It is this attitude that lies at the heart of creative thinking and which should be shaped in the first place.

The formation of an active creative personality is an important task of any actively developing society. The creative activity can be viewed through the structure of personality and activity as an integral quality, expressed in a purposeful unity of needs, interest and actions manifested in creative activity. Many researchers are now trying to gain a deeper understanding of the mechanism for stimulating creativity in order to use it in the new contemporary context. We are witnessing a significant change in the nature of the professional activity, above all the increase in complexity and creativity; it is becoming multidimensional and corporate. The new content of education reflects the social demand for a modern, competitive engineer capable of multilevel social and management modelling, with the necessary skills in a related field. A broad-based training of specialists who are able to work successfully in different enterprises is required. One of the most important factors directly pushing us towards the need to train specialists with a creative potential is the increasing trend towards the growth of knowledgeintensive modern production, which causes the need for advanced personnel, personnel with good fundamental and special training.

\section{Discussions}

The research on the problem of forming the creative potential of future engineers is conditioned by the objective needs in the training of modern engineering personnel. The validity of the obtained results and conclusions formulated in the work is ensured by the adequate definition of the initial methodological positions; reliance on fundamental research; use of a set of empirical and theoretical methods; conducting the experiment under conditions of real educational activity; duration of the experimental work; direct participation of the authors in it, confirmed by the hypothesis put forward in the work. Today we are actually seeing significant changes in the pedagogical activity itself, in the totality of the relationships that arise in the educational process and are expressed in new educational content, forms of organization, innovative learning technologies, and evaluation systems. The pace of modern scientific and technological progress poses a fundamentally new challenge to the education system: to develop an individual performer who responds effectively to constant changes in technology, both in his or her workplace and throughout the technological chain. Modern society needs an anticipatory pedagogy - a system of intellectual and psychological development that forms the stable components of a creative style of thinking in the individual. 
It should be noted that many researchers point out that when developing a creative thought process, the very trajectory to new creative results is paved not only by logical reasoning and calculations, but also by intuition. The focus of modern pedagogy on shaping the qualities of a creative personality in technical university students is changing the forms and principles of pedagogical activity. The key figure in the educational process is the teacher. It is what happens in the classroom that gives meaning to all the activities of the education system. The teacher should not teach, i.e., impart knowledge, but help to learn and develop, not be a source of information, but an organiser of thought activity. Teaching creative thinking, or developing a culture of thinking directly in the educational process, will occur when teaching material is introduced not as descriptive, but as containing a real-world problem, but in such case a methodology for problem solving is needed. Many researchers agree that creative, intellectual capacity is a relatively stable structure of mental ability. A number of researchers highlight that the main characteristics of creative intellectual capacity are the ability to think dialectically, which involves spontaneous, operational, heuristic and dialectical-heuristic levels. Considering the priorities in formation of students' creative thinking in technical university, it is important to emphasize the necessity of strengthening fundamentalization in educational activity in higher education institution, formation of methodological, creative culture in future specialists on a constant basis. Fundamentalization today is one of the main directions of education paradigm development. Research in recent years has shown that "creativity» is not some special characteristic of cognitive processes, but is one of the deepest characteristics of personality. A personality cannot be «shaped», it can only be nurtured. Upbringing, in turn, cannot be anything other than the creation of conditions for self-education of a personality.

There is reason to believe that what matters most for students' creative thinking is that the subject has the internal resources necessary to identify the barrier (the task) and to carry out the transference. This is particularly striking when analysing the higher levels of creative thinking manifested in scientific discoveries and major inventions. A number of researchers point out that the current educational system, including problem-based learning, has certain shortcomings when it comes to the development of creative thinking. Of course, this system teaches how to cope successfully with school tasks. But whether it develops creativity is still in question. The key to creativity is unconscious association by resemblance, which ensures the identification of the transposition task. And school teaches only logical analysis, which never leads to discovery. In order to prove the impact of «developmental» learning on the increase of personal creativity, we have to follow the life trajectory of school leavers who have been trained in traditional and «developmental» methods.

As for «student», reproductive creativity, it follows the full thought cycle, including all four of its phases. During reproductive creativity there are also cognitive-transformative barriers, but learners are provided with all the necessary identification, analytical and performing programmes. They are enough even to overcome non-routine barriers. Non-routine here does not mean the complete absence of analytical-identification programmes, but rather the need to choose from several programmes or to combine them. The problem of updating identifiers and operating programmes is also greatly simplified. When preparing for tests and examinations, the student refreshes his or her memory of the knowledge and skills that may be useful in identifying and solving certain types of examination problems in advance. The learner acts according to known rules even when solving complex tasks broken down into many subtasks. This kind of analysis requires the ability to «act in the mind» by retaining a considerable amount of data in memory. The scientific novelty and theoretical significance of the investigated problem lies in the disclosure of the essential features of the complex tasks developed by us on the basis of the principles of professional orientation, continuity, integrity and completeness, which adequately reflect the essential features of the modern engineer's activity. The complex tasks developed and implemented in the classes require the future specialist to integrate diverse knowledge (technical, special, psychological and pedagogical, managerial, etc.). 
The practical significance lies in the fact that a pedagogical model of the process of training future engineers with a creative style of thinking has been developed. The development of a specialist model based on the model of his/her activity provides an opportunity to take a broader look at the problems of training and using specialists, and to assess the quality of work of the various links of the university. Our research confirmed the validity of our hypothesis and at the same time allowed us to see new problems that need to be studied and solved, such as the problem of forming the creative potential of a specialist through the solution of specially developed situations and tasks of a creative nature.

The main results of the study in the form of a work programme and methodological recommendations are used in the practice of teachers at Kazan State University of Architecture and Engineering.

\section{Conclusion}

In the course of the work carried out, good results were obtained. The results confirm that the process of forming creative foundations in students should be oriented towards modern professional activity, which will entail changes in the objectives, content and structure of the training. The authors have developed and substantiated the component composition and peculiarities of psychological and pedagogical conditions for the formation of creative potential in future engineers. Among the highlighted conditions, the targeting of the whole educational process, its content, methods, forms of organisation and means of learning for the gradual formation of the creative foundations of an engineer is mandatory. Thus, today it is especially necessary to shape the creative intellectual potential of engineering students. One of its essential characteristics is the ability to regulate one's own thinking process. Thinking as a cognitive activity develops in the process of overcoming the value and system of cognitive barriers specific to each of its phases. The structure of creative thinking has significant differences due to the inability to carry out the main creative act - identification and transference - through logical analysis.

It is necessary to emphasize the practical significance of the performed work. The results obtained and the developed pedagogical model of creative potential formation process in future engineers implemented in Kazan State University of Architecture and Engineering allow increasing the demand for engineering graduates in the labour market in the future.

\section{References}

1. S.A. Atwood, J.E Pretz. Creativity as a factor in persistence and academic achievement of engineering undergraduates, J. Eng. Educ. 105, 540-559 (2016). DOI: 10.1002/jee.20130.

2. I. Badran. Enhancing creativity and innovation in engineering education, Eur. J. Eng. Educ. 35 2, 573-585 (2007). DOI: 10.1016/j.tsc.2017.01.004.

3. D. Cropley, A. Cropley. Engineering creativity: A systems concept of functional creativity, Creativity across domains: Faces of the muse, 169-185 (2005).

4. D.H. Cropley. Promoting creativity and innovation in engineering education, Psychol. Aesthet. Creat. Arts, 9 2, 161-171 (2015). DOI: 10.1037/aca0000008.

5. S.R. Daly, E.A. Mosyjowski, S.L. Oprea, A. HuangSaad, C.M. Seifert. College students' views of creative process instruction across disciplines, Think. Ski. Creat. 22, 1-13 (2016).

6. S. Drabkin. Enhancing creativity when solving contradictory technical problems, J. Prof. Issues Eng. Educ. Pract., 78-82 (1996).

7. M. Karwowski. Creative Mindsets: Measurement, Correlates, Consequences, Psychol. Aesthetics, Creat. Arts, 8 1, 62-70 (2017). 
8. G. Scott, L.E. Leritz, M.D. Mumford. The effectiveness of creativity training: $A$ quantitative review, Creativity Research Journal 16 (4), 361-388 (2004).

9. B. Shneiderman. Creativity support tools: Accelerating discovery and innovation, Commun. ACM 50, 20-32 (2007).

10. R.V.V. Vidal. Creativity for engineers, Lyngby, Denmark, (2003).

11. D.R. Waller. An Exploration of Students' Perceptions of Attitudes towards Creativity in Engineering Education, Queen's University, (2016).

12. L.A. Zampetakis, L. Tsironis, V. Moustakis. Creativity development in engineering education: The case of mind mapping, J. Manag. Dev. 26, 370-380 (2007). DOI: 10.1108/02621710710740110.

13. C. Zhou. Teaching engineering student's creativity: A review of applied strategies, J. Effic. Responsib. Educ. Sci., 5 2, 99-114 (2012).

14. A. Craft. The limits to creativity in education: Dilemmas for the educator, British journal of educational studies, 51 (2), 113-127 (2003).

15. D. Davies, D. Jindal-Snape, C. Collier, R. Digby, P. Hay, A. Howe. Creative Learning Environments in Education - a systematic literature review, Thinking Skills and Creativity, (2013).

16. S.R. Daly, E.A. Mosyjowski, C.M. Seifert. Teaching creativity in engineering courses, J. Eng. Educ. 103 3, 417-449 (2014).

17. R.L. DeHaan. Teaching creativity and inventive problem solving in science, CBE-Life Sciences Education 8 (3), 172-181 (2009).

18. R.M. Felder. On creating creative engineers, Eng. Educ. 77, 222-227 (1987).

19. R.M. Felder, D.R. Woods, J.E. Stice, A. Rugarcia. The future of engineering education II. Teaching methods that work, Chem. Eng. Educ. 34, 26-39 (2000).

20. E. Hong, Y. Peng, H.F. O'Neil. Activities and Accomplishments in Various Domains: Relationships with Creative Personality and Creative Motivation in Adolescence, Roeper Rev., 36 2, 92-103 (2014).

21. H. Grant, C.S. Dweck. Clarifying Achievement Goals and Their Impact, J. Pers. Soc. Psychol. 85 3, 541-553 (2003).

22. H. Kanematsu, D.M. Barry. Creativity and its importance for education, Intelligent Systems Reference Library 91, 3-7 (2016). DOI: 10.1007/978-3-319-19234-5_1.

23. K. Kazerounian, S. Foley. Barriers to creativity in engineering education: $\bar{A}$ study of instructors and students' perceptions, J. Mech. Des. 129 July 2007, 761-768 (2007).

24. P.G. Klukken, J.R. Parsons, P.J. Columbus. The Creative Experience in Engineering Practice: Implications for Engineering Education, J. Eng. Educ. 86 2, 133-138 (1997).

25.Z. Liu, D.J. Schonwetter. Teaching creativity in engineering, Int. J. Eng. Educ. 20, 801-808 (2004).

26. D. McKeag. Embedding creativity and innovation in the engineering curriculum, Processings of the SEFI Annual Conference, 30 June-3 July (2008).

27. L. Monroy. Teaching Creativity, Procedia - Social and Behavioral Sciences 174, 2795-2797 (2015). DOI: 10.1016/j.sbspro.2015.01.969.

28. S.H. Parka, K.K. Kimb, K.H. Lee. A Neuro-Educational Study of The Development of The Creativity Based Teaching Program and Its Effect, Procedia - Social and Behavioral Sciences 186, 1-8 (2015). DOI: 10.1016/j.sbspro.2015.04.200.

29. L.G. Richards. Stimulating Creativity: teaching engineers to be innovators, The Frontiers in Education Conference, FIE'98, $28^{\text {th }}$ Annual, (1998).

30. F. Saliceti. Educate for Creativity: New Educational Strategies, Procedia - Social and Behavioral Sciences 197, 1174-1178 (2015). DOI: 10.1016/j.sbspro.2015.07.374.

31.L.S. Shulman. Knowledge and Teaching: Foundations of the new reform, Harvard Educational Review 57, 1-22 (1987). 
32. P.E. Vernon, J.A. Glover, R.R. Ronning, C.R. Reynolds. The Nature-Nurture Problem in Creativity, Handbook of Creativity, Eds. Springer US, 93-110 (1989).

33. C. Zhou. Teaching engineering student's creativity: A review of applied strategies, J. Effic. Responsib. Educ. Sci. 5 2, 99-114 (2012).

34. M. Zivitere, V. Riashchenko, I. Markina. Teacher - Pedagogical Creativity and Developer Promoter, Procedia - Social and Behavioral Sciences 174, 4068-4073 (2015). DOI: 10.1016/j.sbspro.2015.07.374.

35. T.M. Amabile, E. Tighe. Questions of creativity, Creativity. The Reality Club, J. Brockman, Ed. New York: Simon \& Schuster, 7-27 (1993).

36. D.H. Cropley, A.J. Cropley. Functional Creativity, «Products» and the Generation of Effective Novelty, The Cambridge Hand-book of Creativity, Cambridge University Press, New York, pp. 301-317 (2010).

37. H.B. Parkhurst. Confusion, lack of consensus, and the definition of creativity as a construct, Journal of Creative Behavior 33 (1), 1-21 (1999).

38. V. Prabhu, C. Sutton, W. Sauser. Creativity and certain personality traits: Understanding the mediating effect of intrinsic motivation, Creat. Res. J. 20 1, 53-66 (2008).

39. M.A. Runco, G.J. Jaeger. The standard definition of creativity, Creat. Res. J. 24 1, 92-96, (2012).

40. R.J Sternberg, J.C. Kaufman. Constraints on creativity, The Cambridge handbook of creativity, 467-482 (2010).

41. R.J. Sternberg. The Nature of Creativity, Creativity Research Journal 18 1, 87-98 (2006).

42. S. Zappe, I. Mena, T. Litzinger. Creativity is not a purple dragon, NCIIA's $17^{\text {th }}$ Annual Conference, 1-13 (2013). 